\title{
Tones from a Narrowing Race: Polling and Online Political Communication during the 2014 Scottish Referendum Campaign
}

\author{
EVELYNE BRIE AND YANNICK DUFRESNE*
}

\begin{abstract}
The use of negative political communication is a predominant characteristic of modern politics. However, literature doesn't provide an answer to the following question: what explains fluctuations in the use of negative messages within political organisations during a given political campaign? The present paper examines this question in the context of the 2014 Scottish independence referendum. Data consists of all tweets distributed by the official Twitter account of both campaign organisations (@YesScotland and @UK_Together) between June 16, 2014 and September 17, 2014. Results are obtained by a non-parametric local regression and by time-series regression analyses. Our model demonstrates that having an advance in the polls had a statistically significant influence on the tweet sentiment of at least one organisation during the referendum campaign: Better Together's messages were more negative when it was ahead in the polls. Meanwhile, Yes Scotland's messages were more negative after each of the leaders' debates.
\end{abstract}

Keywords: Sentiment Analysis; Twitter; Referendum; United Kingdom; Scotland

In political campaigns, tone matters. Scholarly research has suggested that negative political communication could affect both political preferences ${ }^{1}$ and voter turnout ${ }^{2}$, and accumulating evidence in psychology shows that negative emotions typically prevail over positive ones, both at the social and individual level. ${ }^{3}$ Politicians thus have clear incentives to go negative: such messages generally attract more attention and are more likely to be remembered by voters than positive messages. ${ }^{4}$ We should therefore expect political organizations to go negative when it serves their goals. But do they? And what explains tone variations of political communication within campaigns?

The present article examines online political communication of the official YES and NO umbrella organizations during the 2014 Scottish independence referendum campaign. This context offers unique opportunities to study political communication dynamics: two clearly defined sides competed to convince voters to choose between status quo and a hopeful but risky change. Previous research has shown that defenders of the status quo in independence referenda - here, the Better Together (NO) organization - have greater strategic incentives to go negative than pro-secession organizations like Yes Scotland (YES). ${ }^{5}$ Accordingly, our sentiment analysis of social media posts

* Department of Political Science, University of Pennsylvania (E-mail: ebrie@ sas.upenn.edu); Département de Science Politique, Université Laval (E-mail: yannick.dufresne@pol.ulaval.ca). Data replication sets are available in Harvard Dataverse at https://dx.doi.org/10.7910/DVN/RQ7P1F and online appendices at: https://doi. org/10.1017/S0007123417000606

1 Richard R. Lau and Gerald M. Pomper 2002.

2 Stephen Ansolabehere et al. 1994; Stephen Ansolabehere, Shanto Iyengar, Nicholas Valentino and Adam Simon 1999.

3 Tiffany A. Ito, Jeff T. Larsen, N. Kyle Smith, John T. Cacioppo 1998; Maria Jarymowicz and Daniel Bar-Tal 2006.

${ }^{4}$ Samuel D. Bradley, James R. Angelini, and Sungkyoung Lee 2007; Michael A. Shapiro and Robert H. Rieger 1992.

5 Richard Nadeau, Pierre Martin, and André Blais 1999, 536. 
shows that the NO campaign was generally more negative than the YES campaign during the Scottish independence referendum. However, results suggest that contextual factors were also at play. Indeed, the tightening of the race appears to have had a significant effect on Better Together's campaigning tone. Moreover, data shows that Yes Scotland's communication sentiment might have been impacted by the broadcasting of two televised leaders' debates in August 2014.

\section{LITERATURE REVIEW}

\section{Negativity in Political Campaigns}

The use of negative political communication is a predominant characteristic of modern politics, ${ }^{6}$ with research showing that approximately one-third of all campaign communication is negative. ${ }^{7}$ This practice can be explained by the theory of negative voting, which states that vote choice is primarily determined by negative considerations and by the rejection of proposals rather than by their endorsement. $^{8}$ That line of reasoning seems to have found an echo on the field: nowadays, most political strategists consider negative communication as an effective strategy in electoral contexts, ${ }^{9}$ even if accumulating evidence shows that negative messaging can often backfire and harm its users. ${ }^{10}$

More broadly, by the use of framing, any given message can be considered through a variety of perspectives and be constructed so as to have implications for several values or considerations. ${ }^{11}$ According to Hallahan, ${ }^{12}$ framing distorts cognitive information processing by incorporating contextual clues in a message. One of the frames of Hallahan's seminal framing typology - the framing of choice (or 'framing of risk' for Strömbäck and Kiousis ${ }^{13}$ ) - models reality by articulating a choice between two independent options involving a lower or higher degree of uncertainty. Independence referenda are an excellent example of this type of framing, as the status quo option is generally opposed to a radical (and unpredictable) change in a region's legal status. Furthermore, prospect theory, which is intimately related to the framing of choice, states that the negative framing of a risky decision is reflected more fully ${ }^{14}$ and receives more attention, ${ }^{15}$ when compared to a logically equivalent option that is positively framed. This may seem counterintuitive for two reasons: first, because the receiver should calculate gains and losses without being influenced by an arbitrary positive or negative reference point, and second, because the evocation of a gain or a loss should not affect attitude towards uncertainty. ${ }^{16}$ Nonetheless, researchers are able to explain prospect theory by the fact that people generally tend to be risk averse. ${ }^{17}$

In sum, the framing of choice presents each electoral outcome as a decision between multiple avenues among which adverse options are strategically being pictured as more risky. ${ }^{18}$ Research shows that such framing can take up two different forms. First, political organizations may use fear arousal campaigning, which is typically 'designed to scare people by describing the terrible things

6 Sharyne Merritt 1984, 27.

7 Larry J. Sabato 1981, 165.

8 Campbell et al.,1960, 554; Samuel Kernell 1977. Angus Campbell, Philip Converse, Warren Miller, Donald Stokes (Campbell et al., 1960).

9 Paul Taylor 1989.

10 Ronald Faber, Albert Tims, and Kay Schmitt 1993; Gina M. Garramone 1985; Ronald Paul Hill 1989.

11 Dennis Chong and James N. Druckman 2007, 104.

12 Kirk Hallahan 1999, 208.

13 Jesper Strömbäck and Spiro Kiousis 2011.

14 David L. Hamilton and Mark P. Zanna 1972.

15 Dirk Wentura, Klaus Rothermund, and Peter Bak 2000, 1035.

16 Jonathan Mercer 2005, 1.

17 Daniel Kahneman and Amos Tversky 1979.

18 Strömbäck and Kiousis 2011, 186. See above. 
that will happen to them if they do not do what the message recommends'. ${ }^{19}$ Second, political communication can rely on critical campaigning, which argues in a more civil manner against specific public policies. ${ }^{20}$ In this article, data show that the Scottish referendum campaign communication generally lies within critical campaigning, with few extreme messages and less than half of all published messages framing the outcome of the referendum as either a gain or a loss. ${ }^{21}$ Interestingly, for Better Together, most of the framed messages (65.45 per cent) concentrate on losses associated with a YES vote, while the reverse tendency is observable for Yes Scotland, which rather focuses on predicted gains in an independent Scotland (81.42 per cent). This is both consistent with our findings and with the work of Nadeau et al., ${ }^{22}$ which state that negative campaigning tends to be especially effective for the status quo option during independence referenda.

\section{The 2014 Scottish Independence Referendum}

Referenda are unique opportunities for the study of negative communication, for three main reasons. First, referenda focus, by definition, on positional issues. Even if they cannot always be considered as being cross-partisan, issue-based contests are necessarily more prone to campaign effects. ${ }^{23}$ Second, political options in referenda are usually defined in two distinct camps, which eases direct comparison in the study of interactions. Third, dichotomous competition is thought to favour negative messaging by making the potential increase in public support for a certain camp directly dependent on deterring support for the other camp. For instance, '[if] there were only two brands of cereal, dissuading customers from purchasing the competitor's brand would benefit the sponsor because it would leave only the sponsor's brand to purchase'. ${ }^{24}$

In 2011, the Scottish National Party formed the first majority government at the Scottish Parliament in Holyrood on the promise of holding a referendum on Scottish independence. On 15 October 2012, Scotland's first minister Alex Salmond ratified the Edinburgh Agreement with the British government to set the terms of the Scottish independence referendum campaign, which was officially launched mid-2014. Two umbrella organizations representing the YES and NO forces were created: Yes Scotland and Better Together. Both were legally accredited and received public funding to transmit their messages on various platforms. Throughout the campaign, risks associated with the secession of Scotland occupied a central place in the arguments of the Better Together organization. More precisely, the NO camp favoured themes that were particularly focused on the insecurity related to the use of the British currency, the status of Scotland in the European Union and the transition of the national health system. ${ }^{25}$

Figure 1 shows the evolution of public opinion in the referendum campaign from 16 June to 17 September 2014. In June 2014, the NO option was comfortably leading the polls with a 17 per cent advance on the YES, but gradually lost momentum during the last weeks of the campaign. In August, two televised debates took place between Scotland's pro-independence First Minister Alex Salmond and Chairman of the Better Together campaign Alistair Darling. The first debate, which aired on Scottish Television on 5 August, was considered a win for the NO campaign by 56 per cent of viewers. ${ }^{26}$ However, Salmond came out on top in the second debate broadcasted on BBC One

19 Kim Witte 1992, 329.

${ }^{20}$ Kim L. Fridkin and Patrick J. Kenney 2011, 308.

21 For Better Together and Yes Scotland, respectively 36.67 per cent and 46.67 per cent of messages portrayed a framing of choice, for a random sample of 300 manually coded messages.

22 Nadeau, Martin, and Blais 1999. See above.

23 Lawrence LeDuc 2002, 145.

24 Merritt 1984, 27. See above.

25 Chris Green, Nigel Morris, Jonathan Brown, James Cusick 2014.

26 Herald Scotland 2014. 


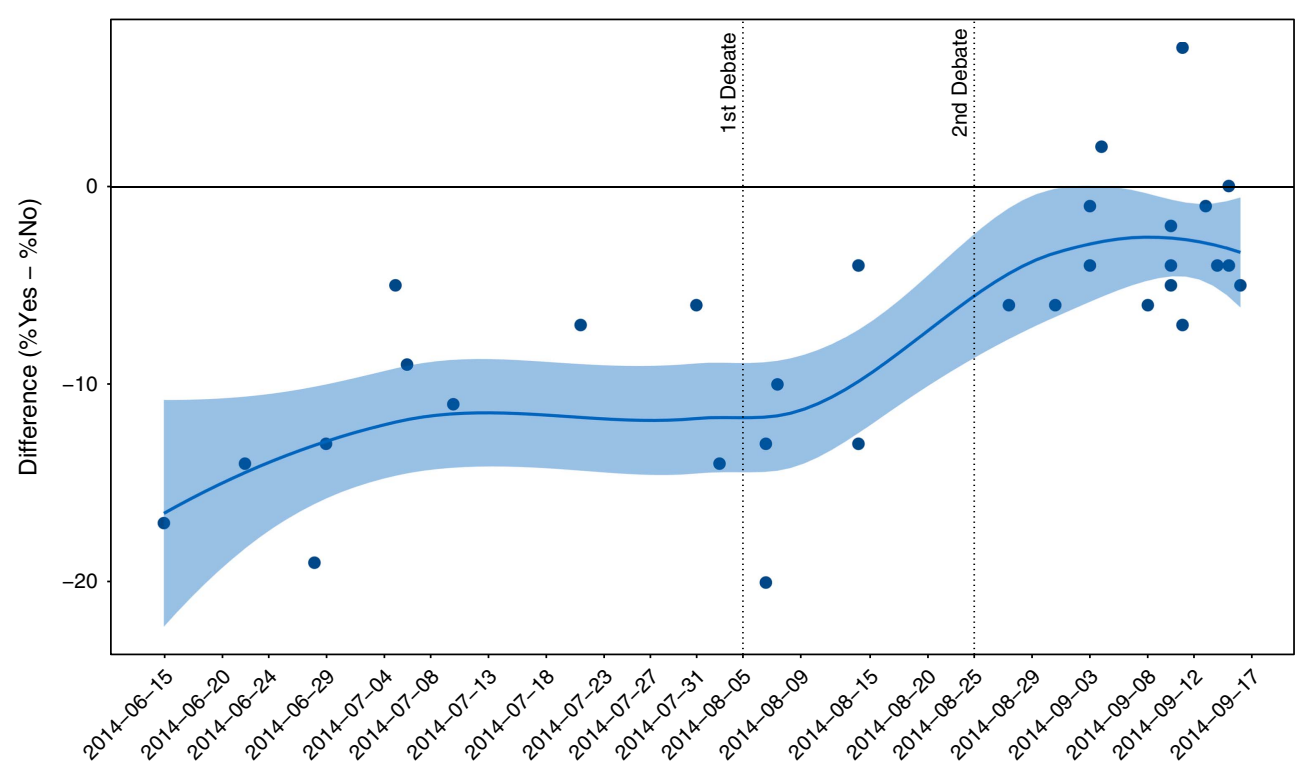

Fig. 1. The evolution of public opinion in the referendum campaign.

Source: What Scotland Thinks (16 June to 17 September 2014).

Note: Figure 1 shows the evolution of tightness of the Scottish referendum race. Each dot represents a poll. The score on the y-axis is calculated by subtracting the percentage of support for the YES option from the one for the NO option in each poll. Hence, the black horizontal line shows the score level representing an equality of support between the two options. Non-parametric local regression (lowess) is used to illustrate this trend. The 95 per cent confidence intervals are calculated using a t-based approximation.

Scotland on 25 August according to 71 per cent of viewers. ${ }^{27}$ On referendum day 18 September, the Scottish electorate decided to remain within the Union by a clear 55.3 per cent majority.

\section{DATA AND METHOD}

Political parties increasingly craft their electoral strategies for the use of social media platforms in a top-down manner. ${ }^{28}$ Indeed, despite the inter-user interactivity of social media and the framing of traditional media, political elites remain firmly in control of their messaging. ${ }^{29}$ This article analyses the Twitter communication of the two official organizations involved in the 2014 Scottish referendum: Better Together and Yes Scotland. These textual data were collected throughout the campaign using the Twitter API. Twitter is a micro-blogging website based on real-time diffusion of short text messages and on interactivity between its users, which comprise both individuals and organizations. It constitutes a valuable source of data for the study of political communication, as it is largely used for political message diffusion and offers a unique opportunity for political figures to interact with potential voters. ${ }^{30}$

Over the past few years, some doubt has been casted on the representativeness of Twitter users within the broader electorate. While it has been clearly demonstrated that these users have sociodemographic characteristics that are different from those of the

27 Severin Carrell and Libby Brooks 2014.

28 Michael Karlsson, Christer Clerwall, and Ulf Buskqvist 2013, 17.

29 Günther Lengauer and Iris Höller 2013.

30 Andranik Tumasjan, Timm O. Sprenger, Philipp G. Sandner, Isabell M. Welpe 2010, 180. 
general public, ${ }^{31}$ researchers have developed various weighting methods to ensure their representativeness. ${ }^{32}$ However, contrarily to this stream of literature, our analysis does not seek to infer characteristics of the general population by using Twitter data - instead, we regard organizational tweets as a proxy for the general political communication emitted by Yes Scotland and Better Together throughout the referendum campaign. Although the analysis of organizational political communication on Twitter has widely been neglected by the literature, Tumasjan et al. ${ }^{33}$ demonstrate that Twitter message sentiment tends to reflect offline party positioning. These findings confirm our assumption that the social media communication diffused during the 2014 Scottish referendum approximately reflects each of the two official organizations' global communication strategy.

Furthermore, the structure of Twitter data allows us to look at the interaction of political actors with other Twitter users, notably with regard to the 'retweet' function, which permits the sharing of messages composed by third parties. The real-time aspect of this platform also enables us to study the evolution of political actors' messaging tone and content during every single day of the campaign. We collected all messages diffused by the two official Scottish referendum organization accounts (@YesScotland, $\mathrm{N}=3,078$ and @UK_Together, $\mathrm{N}=1,230$ ) during the last three months of the campaign. Our analyses are based on an automated sentiment analysis of these textual data, using the sentiment lexicons developed by Liu, $\mathrm{Hu}$, and Cheng ${ }^{34}$ - a well-known method in the field of political communication. A polarity score was assigned to each individual tweet based on the words that compose it: messages were given a score point for each positive word recognized by the lexicons and lost one of these score points for each negative word recognized by the lexicons.

The literature using Twitter data frequently relies on similar lexicon-based sentiment analyses. Recent studies show that the reliability of such lexicons can be comparable to that of manual coding. ${ }^{35}$ For instance, Chew and Eysenbach ${ }^{36}$ demonstrate that the evaluation of Twitter communication trends over time is typically similar with both methods. Research also shows that, by their very nature, short messages like tweets are easier to analyse efficiently using automated methods than larger texts or documents. ${ }^{37}$ Furthermore, if the number of observations is relatively large, as is the case in our analysis, errors linked with automated sentiment coding typically cancel out. ${ }^{38}$ Still, some authors have suggested that the simplicity of automated methods could make their results sensitive to noise. ${ }^{39}$ This advocates for an adjustment of the lexicons to their specific application context. Thus, to avoid unnecessary bias, neither the word 'Yes' or 'No' were included in the lexicons used in our analysis, nor were the words related to slogans 'Better' (was removed from the original dictionary) and 'Together'. ${ }^{40}$ An example of coding can be found in the following tweet diffused by Better Together, which

\footnotetext{
31 Pascal Jürgens, Andreas Jungherr, and Harald Schoen 2011; Alan Mislove Sune Lehmann, Yong-Yeol Ahn, Jukka-Pekka Onnela, J. Niels Rosenquist 2011.

${ }^{32}$ Pablo Barberá and Gonzalo Rivero 2015; Daniel Gayo-Avello 2011; Erik Tjong Kim Sang and Johan Bos 2012.

${ }^{33}$ Tumasjan et al. 2010, 178. See above.

34 Bing Liu, Minqing Hu, and Junsheng Cheng 2005.

35 Hiroshi Kanayama and Tetsuya Nasukawa 2006; Alexander Pak and Patrick Paroubek 2010.

36 Cynthia Chew and Gunther Eysenbach 2010, 8.

37 Sagar Butha Uchit Doshi, Avit Doshi, Meera Narvekar 2014, 583.

38 Brendon O'Connor, Ramnath Balasubramanyan, Bryan R. Routledge, Noah A. Smith 2010, 125.

39 Panagiotis Metaxas, Eni Mustafaraj, and Daniel Gayo-Avello 2011, 168.

40 Robust tests also suggested the removal of the word 'Darling' from our lexicons. The word is associated with positive sentiment scores, although its use during the 2014 Scottish referendum was mostly exclusively referring to Alistair Darling, the leader of the NO-side campaign.
} 
has a score of -3 due to the presence of three negative words ('breaking', 'risk' and 'unwilling'):

@UK_Together: Brian Wilson says breaking away from the UK is a risk rural communities seem unwilling to take. (4 August 2014)

Similarly, the following Yes Scotland tweet holds a score of 2 since it contains two positive words ('wealth' and 'decent'):

@ YesScotland: With a Yes, we can make Scotland's wealth work better - creating better jobs, providing decent pensions and investing in childcare. (15 July 2014)

In supplement to social media data, our analyses use commercial polling data publicly available on the 'What Scotland Thinks?' website run by the ScotCen Social Research. ${ }^{41}$ It provides impartial, up-to-date information on public attitudes towards the issue of Scottish independence. Data show the answers to the following survey question for thirty-six polls throughout the campaign: 'Should Scotland be an independent country?' $(\mathrm{N} \in\{705,3,237\})$.

\section{RESULTS}

Our results show a sharp contrast in the communication tone of Better Together and Yes Scotland during the 2014 Scottish independence referendum campaign. As expected, the NO side's political messaging was more negative than that of the YES side, but the tone of both organizations also fluctuated over time. Among others, Yes Scotland became distinctively more negative as time passed, especially after crucial events like the televised debates. What could explain such variations? At this point in time, scholars have not studied the impact of fluctuations in vote intentions - as reported by polls - on an organization's use of negative communication during political campaigns. In the literature, public opinion is rather used as an explicative variable for other trends: turnout level, ${ }^{42}$ mass media behaviour ${ }^{43}$ or polling behaviour itself. ${ }^{44}$ Our article builds on this previous work by analysing the effect of public opinion on political communication sentiment. We use a time-series regression analysis to sort out the potential determinants of tone variation. Results demonstrate that, controlling for momentum, campaign day, campaign events and the dates on which polls were released, tone scores correlate with standings in polls for the NO side, and with campaign periods for the YES side. These findings are discussed in more detail below.

Figure 2 shows tweet sentiment distribution of all messages diffused by both official Twitter accounts during the Scottish referendum campaign. Overall, for both campaigns, few tweets have extreme sentiment values; the majority are neutral or moderately positive. We also note that Yes Scotland's tweets are clearly more positive than those of Better Together. As stated earlier, this is consistent with previous research looking at the 1995 Quebec independence referendum, which suggests that campaigning on the side of the status quo provides 'an incentive to exploit [worst-case] scenarios'. ${ }^{45}$ However, the fact that Better Together's communication is only negative when compared to Yes Scotland, and not negative per se, confronts some separatists' claim that Better Together's campaign was outright 'scaremongering'. 46

41 See www.whatscotlandthinks.org. Polling by YouGov, TNS-BMRB, ICM, Survation, Panelbase, Ipsos Mori and Opinium.

42 Stephen Ansolabehere and Shanto Iyengar 1994; Jens Großer and Arthur Schram 2010.

43 Charles K. Atkin and James Gaudino 1984.

44 Stephen J. Ceci and Edward L. Kain 1982; Ian McAllister and Donley T. Studlar 1991; Vicki G. Morwitz and Carol Pluzinski 1996.

45 Nadeau, Martin and Blais 1999, 536. See above.

46 Scottish National Party 2014. 


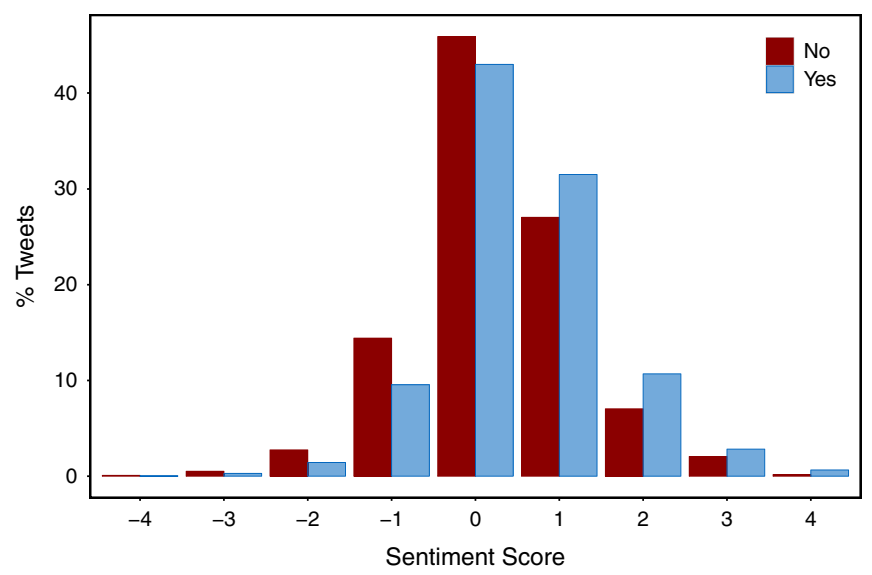

Fig. 2. Tweet sentiment distribution of all messages diffused by both official Twitter accounts during the Scottish referendum campaign.

Source: Official Twitter accounts of Better Together $(\mathrm{N}=1,230)$ and of Yes Scotland $(\mathrm{N}=3,078)(16$ June to 17 September 2014).

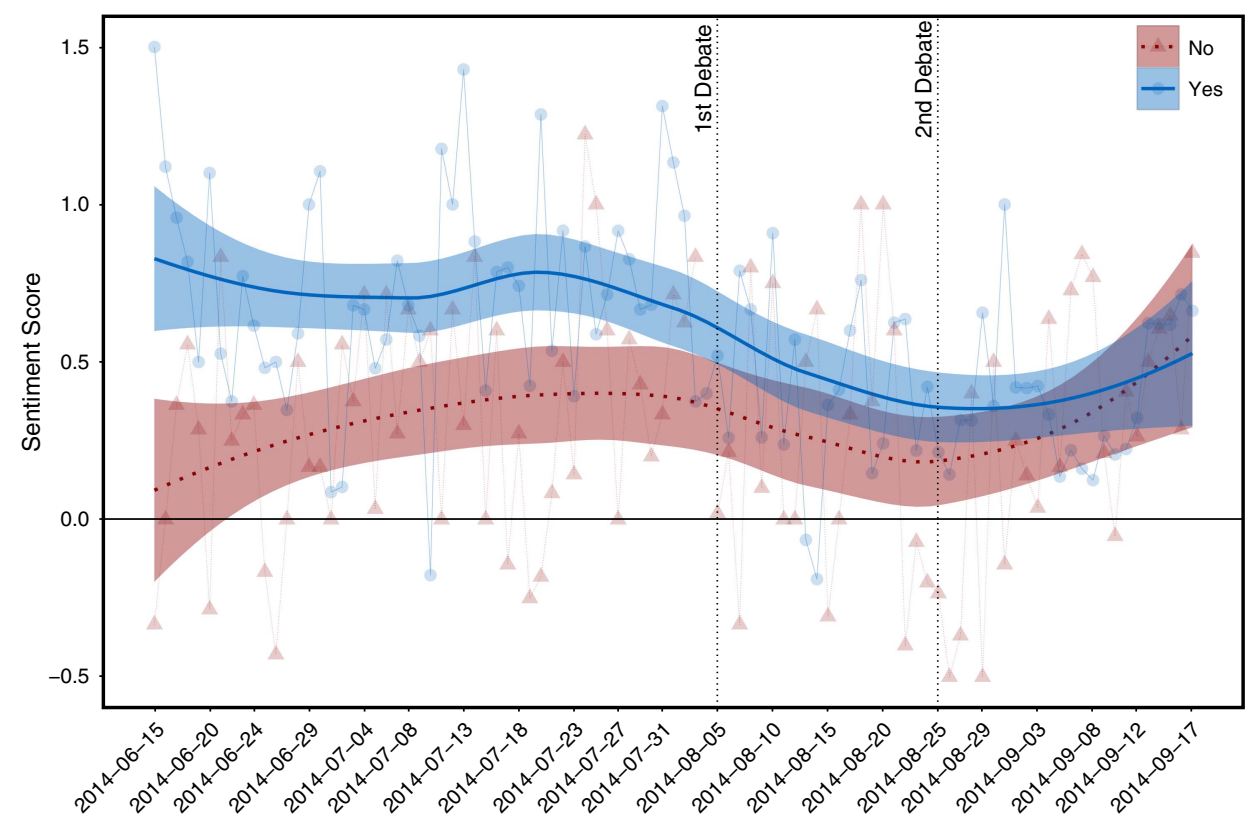

Fig. 3. The daily evolution of tweet sentiment.

Source: Official Twitter accounts of Better Together $(\mathrm{N}=1,230)$ and of Yes Scotland $(\mathrm{N}=3,078)$ (16 June to 17 September 2014). The first and second televised debates were respectively held on 5 and 25 August 2014.

Figure 3 shows the daily evolution of tweet sentiment for both organizations from 16 June to 17 September 2014. Each dot represents the daily average sentiment score for each side. These dots are connected by a thin solid line representing the raw evolution of tweet sentiment. The thicker lines represent the results of non-parametric local regressions (lowess) used to uncover general trends, with 95 per cent confidence intervals calculated using a t-based approximation. 
Results clearly show that the YES side campaign tone gets more negative as time passes. At the beginning of the campaign, the difference in tone is marked: Yes Scotland's campaign is clearly more positive than that of Better Together, which fits our theoretical expectations and the pattern presented in Figure 2. However, the difference in tone between both organizations vanishes near the end of the campaign.

Observational data indicate that this converging trend starts after the heated televised debates between Salmond and Darling in August 2014. As stated earlier, the first debate (5 August 2014 ) is known to have been won by the NO side unionist leader, while the second (25 August 2014) was allegedly won by the YES side separatist leader. Previous research has shown that televised debates can significantly affect voting preferences, ${ }^{47}$ but generally fail to explore their impact on party strategy. In the Scottish case, could the debates themselves explain variations in campaign tone, or could this phenomenon rather be due to other factors, such as the tightening of the race? Indeed, various circumstances could explain a shift in campaigning tone. First, campaign timing could matter. Campaign events - such as leader debates - held at specific moments during the campaign might influence communication sentiment. The averages of both official campaigns' daily tone $(\mathrm{N}=188)$ are regressed on variables operationalizing these factors using a time-series regression analysis. ${ }^{48}$ More precisely, dummies identifying postdebate periods are included in this model, as well as a daily time variable designed to capture the effect of getting closer to referendum day, thus controlling for time trends in tweet sentiment for both organizations.

Second, standings in the polls might push political organizations to change the tone of their messaging out of disappointment or enthusiasm. Therefore, in addition to variables indicating campaign timing, three other variables were created to test the potential effect of public opinion on political communication sentiment. First, the mere difference between the support for each option is used to test whether leading in polls affects campaign tones. Second, since polls also indicate momentum for an option when one of the sides improves its standings, the model includes a momentum variable that is calculated by subtracting the percentage of support for an option in the newest poll from the percentage in the previous poll. Third, polls were frequent during the campaign, but still not released every day. A dummy variable for poll release days is included in the model, since organizations might adopt a different communication strategy on such days. The latest poll numbers were used for days when polls were not released. This choice makes theoretical sense: an option is thought to be ahead in the polls until a new poll is released, and organizations should behave accordingly.

In order to evaluate the effect of each tone predictor, different models are estimated (see Table 1). First, the time-series regression analyses confirm that the NO side was on average more negative than the YES side during the referendum campaign. ${ }^{49}$ But this effect disappears once variables related to public opinion are added to the model. Note that the variable indicating a day during which a poll was released is not statistically significant when considered individually (not shown). When the full model prescribed by theory is estimated, the only potential factor that ends up being statistically significant for the NO side is the effect of leading in polls, once controlled by the other factors. For the YES side, post-debate campaign periods are significantly correlated with political communication sentiment. The direction of the effect is

47 Peter R. Schrott 1990.

48 A first order auto-regressive term was included to control for residual autocorrelation in the model, which is typical of time series data. No substantial difference in the results is detected when adding higher order auto-regressive terms.

49 This observation follows the interpretation of the coefficients for the constant in the models. 
TABLE 1 Testing the effect of public opinion and timing on sentiment score

\begin{tabular}{|c|c|c|c|c|c|c|}
\hline \multirow[b]{3}{*}{ Poll Lead } & \multicolumn{6}{|c|}{ Sentiment Score (Daily Average) } \\
\hline & \multicolumn{3}{|c|}{ YES Campaign } & \multicolumn{3}{|c|}{ NO Campaign } \\
\hline & $\begin{array}{c}0.003 \\
(0.01)\end{array}$ & & $\begin{array}{c}-0.01 \\
(0.01)\end{array}$ & $\begin{array}{c}-0.04 * \\
(0.01)\end{array}$ & & $\begin{array}{c}-0.05 * * \\
(0.02)\end{array}$ \\
\hline Momentum & & $\begin{array}{c}-0.001 \\
(0.01)\end{array}$ & $\begin{array}{c}-0.001 \\
(0.01)\end{array}$ & & $\begin{array}{c}-0.01 \\
(0.01)\end{array}$ & $\begin{array}{c}0.01 \\
(0.01)\end{array}$ \\
\hline Post-debate 1 & & & $\begin{array}{c}-0.31^{*} \\
(0.15)\end{array}$ & & & $\begin{array}{c}0.08 \\
(0.19)\end{array}$ \\
\hline Post-debate 2 & & & $\begin{array}{c}-0.38^{*} \\
(0.18)\end{array}$ & & & $\begin{array}{c}-0.20 \\
(0.24)\end{array}$ \\
\hline Poll Day & $\begin{array}{c}0.14 \\
(0.07)\end{array}$ & $\begin{array}{c}0.15^{*} \\
(0.07)\end{array}$ & $\begin{array}{c}0.15^{*} \\
(0.07)\end{array}$ & $\begin{array}{c}0.03 \\
(0.09)\end{array}$ & $\begin{array}{c}0.09 \\
(0.10)\end{array}$ & $\begin{array}{c}0.03 \\
(0.10)\end{array}$ \\
\hline${\text { Sentiment } \text { Score }_{t-1}}_{1}$ & $\begin{array}{l}0.20 * \\
(0.10)\end{array}$ & $\begin{array}{c}0.20^{*} \\
(0.10)\end{array}$ & $\begin{array}{c}0.13 \\
(0.10)\end{array}$ & $\begin{array}{c}0.005 \\
(0.10)\end{array}$ & $\begin{array}{c}0.08 \\
(0.10)\end{array}$ & $\begin{array}{c}-0.05 \\
(0.11)\end{array}$ \\
\hline Days to Referendum & $\begin{array}{l}0.003 * * \\
(0.001)\end{array}$ & $\begin{array}{c}0.003 * \\
(0.001)\end{array}$ & $\begin{array}{c}-0.002 \\
(0.003)\end{array}$ & $\begin{array}{c}0.0002 \\
(0.002)\end{array}$ & $\begin{array}{c}0.001 \\
(0.002)\end{array}$ & $\begin{array}{c}-0.002 \\
(0.004)\end{array}$ \\
\hline Constant & $\begin{array}{l}0.27 * * * \\
(0.08)\end{array}$ & $\begin{array}{l}0.27 * * \\
(0.08)\end{array}$ & $\begin{array}{l}0.74 * * \\
(0.22)\end{array}$ & $\begin{array}{c}0.29 * \\
(0.10)\end{array}$ & $\begin{array}{c}0.23^{*} \\
(0.10)\end{array}$ & $\begin{array}{c}0.45 \\
(0.28)\end{array}$ \\
\hline $\begin{array}{l}\mathrm{N} \\
\mathrm{R}^{2}\end{array}$ & $\begin{array}{r}94 \\
0.18\end{array}$ & $\begin{array}{r}94 \\
0.18\end{array}$ & $\begin{array}{c}94 \\
0.23\end{array}$ & $\begin{array}{r}94 \\
0.11\end{array}$ & $\begin{array}{c}94 \\
0.03\end{array}$ & $\begin{array}{r}94 \\
0.15\end{array}$ \\
\hline
\end{tabular}

$* \mathrm{p}<0.05 ; * * \mathrm{p}<0.01 ; * * * \mathrm{p}<0.001$.

Source: Official Twitter accounts of Better Together $(\mathrm{N}=1,230)$ and of Yes Scotland $(\mathrm{N}=3,078)$, and What Scotland Thinks (16 June to 17 September 2014).
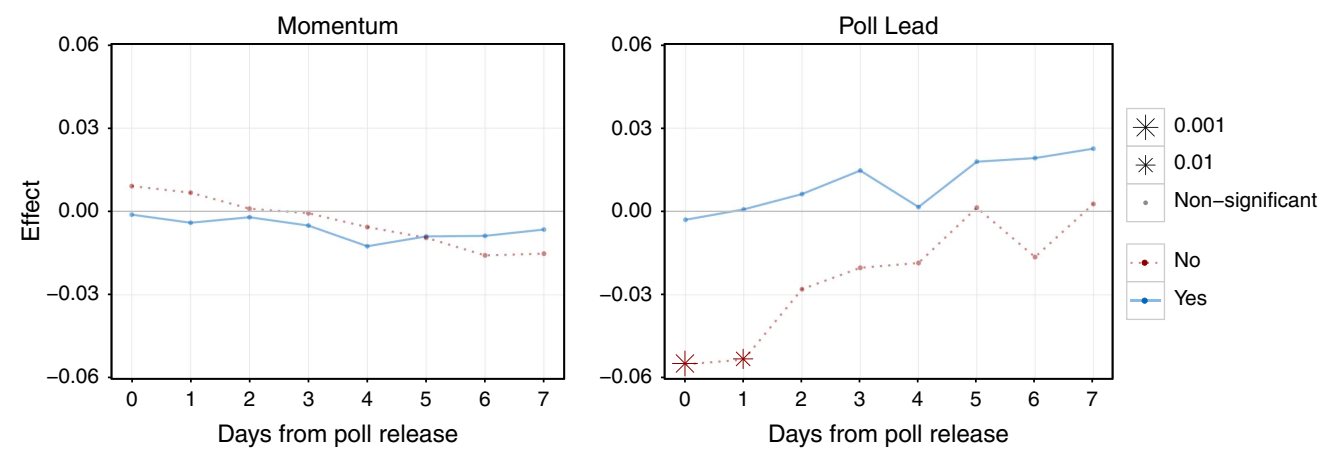

Fig. 4. The evolution of the effect of momentum and poll lead on message sentiment during the week following poll releases.

Source: Official Twitter accounts of Better Together $(\mathrm{N}=1,230)$ and of Yes Scotland $(\mathrm{N}=3,078)$, and What Scotland Thinks (16 June to 17 September 2014).

Method: Linear Regression.

the same for both sides: the more polls were favorable to the NO side, the more Better Together distributed negative messages, and after the first and second debates, the YES side also tended to distribute more negative messages.

Another interesting finding is the existence of a short lagged effect for poll lead on Better Together's communication tone during the campaign. Figure 4 presents the evolution of the effect of momentum and poll lead on message sentiment during the week following poll 
releases. No matter the time lapse following a reported change in momentum, this variable remains uncorrelated with the campaign sentiment of both organizations, which is consistent with the results presented in Table 1. Poll lead, on the other hand, appears to have a statistically significant effect on Better Together's tone only on poll release days and during the following twenty-four hours, which is theoretically consistent with the instantaneity of Twitter communication.

\section{DISCUSSION}

What do these findings mean for the literature on political communication? Research has extensively studied voters' responses to political campaigning. Our data shows that an analysis of the reverse relationship is possible. For instance, public opinion appears to be a predictor of Better Together's communication sentiment during the referendum campaign. Moreover, our model suggests that campaign events such as televised leaders' debates could also have a measurable effect on organizations' communication strategy. In this case, Yes Scotland became more negative after the first debate between Alex Salmond and Alistair Darling, which was broadcasted on Scottish Television (STV) on 5 August 2014. More generally, at that exact point in time, the error margins of both organizations' average sentiment score collided, mostly because of a tone decrease in Yes Scotland's messages. Let's underline again that the NO side had won this first debate, during which Alistair Darling had repeatedly urged Alex Salmond to give out his 'Plan B' if a currency union with the United Kingdom were to be rejected by Westminster. Thus, while our study demonstrates the relevance of using online social media data to analyse elites' strategic political behaviour, results suggest that public opinion is only one of many influences over campaign tone in referendum campaigns.

Furthermore, this article focused on a single case - yet there might be something specific about Scotland or its political actors that explains the results shown in this research. For instance, there were substantial technical differences between both Scottish referendum organizations: the Yes Scotland account had more followers on social media and a greater follower increase than Better Together during the campaign, ${ }^{50}$ and Better Together was 'much more centralized and its grasp over both the message content and the means of communication used by activists more extensive than the Yes campaign, which allowed its activists and subcampaigning groups more leeway and spontaneity'. ${ }^{51}$ These two technical distinctions might have introduced some selection bias throughout the campaign. At the very least, such contextual factors deserve more attention in the developing of a general theory of communication sentiment in referenda.

Overall, online communication data have a great potential for multiple research angles in political science. Interestingly, our results show a sharp contrast of sentiment between primary and secondary political messages for both organizations. If one only looks at the primary messages written by the official accounts, messages produced by the YES side are substantially more positive than those produced by the NO side (see Figure 2). Surprisingly, perhaps, the secondary messages - written by third parties, or 'retweets' - shared by both accounts show the opposite pattern. This supports the conception that the main function of retweeting is to diffuse information that differs from politicians' planned communication strategies. ${ }^{52}$ More studies should be conducted to uncover the exact causes of the differences between primary and

50 Mark Shephard and Stephen Quinlan 2014.

51 Kevin Adamson and Peter Lynch 2014, 43.

52 Sofus A. Macskassy and Matthew Michelson 2011. 
secondary social media messaging in such contexts. Past research already shows that emotional appeals in a tweet, either positive or negative, have positive effects on its 'retweet' rate. ${ }^{53}$ This would imply that political organizations have a tendency to 'retweet' messages that have extreme sentiment scores. Here, in both cases, secondary messages rather tend to moderate the tone of official messages, even if they do not seem to be used for similar reasons by both organizations. For instance, we note that the Yes Scotland account retweeted a particularly high number of messages concerning events and happenings such as rallies or mobilization activities. Is this a planned political communication strategy? Or could it be simply that retweets are not monitored as tightly as primary messages by the campaign teams? After all, the real-time and interactive characteristics of social media make it very difficult to plan in advance a strategy to remain 'on message' based on retweets.

In order to evaluate the generalizability of the findings presented in this article, one would have to replicate this research in a number of other contexts. Yet, independence referenda are relatively rare events. We would therefore suggest focusing on identifying general structural determinants of communication tone in a variety of contexts. Are status quo defenders always more negative? Do polls always affect tone in similar ways and with a similar strength? More research needs to be done on this topic. Some could also reproduce our work in conventional electoral contexts by looking at incumbents as status quo defenders. Finally, on a more technical level, studying political communication in real time has only been recently made possible through social media. More efforts are thus required to explore these new types of publicly available data, which have the potential to contribute to our understanding of real-time political communication dynamics.

\section{REFERENCES}

Adamson, K., and P. Lynch. 2014. The Scottish National Party and the 2014 Independence Referendum. Cardiff: Welsh Academic Press.

Ansolabehere, S., and Shanto Iyengar. 1994. Of Horseshoes and Horse Races: Experimental Studies of the Impact of Poll Results on Electoral Behavior. Political Communication 11 (4):413-30.

Ansolabehere, S., Shanto Iyengar, A. Simon, and N. Valentino. 1994. Does Attack Advertising Demobilize the Electorate? American Political Science Review 88 (4):829-38.

Ansolabehere, S., Shanto Iyengar, and Adam Simon. 1999. Replicating Experiments Using Aggregate and Survey Data: The Case of Negative Advertising and Turnout. American Political Science Review 93 (4):901-09.

Atkin, C., and J. Gaudino. 1984. The Impact of Polling on the Mass Media. Annals of the American Academy of Political and Social Science 472 (1):119-28.

Barberá, P., and G. Rivero. 2015. Understanding the Political Representativeness of Twitter Users. Social Science Computer Review 33 (6):712-29.

Bhuta, S., A. Doshi, U. Doshi, and M. Narvekar. 2014. A Review of Techniques for Sentiment Analysis of Twitter Data. International Conference on Issues and Challenges in Intelligent Computing Techniques (ICICT), February: 583-91.

Bradley, S. D., J. R. Angelini, and S. Lee. 2007. Psychophysiological and Memory Effects of Negative Political Ads: Aversive, Arousing, and Well Remembered. Journal of Advertising 36 (4):115-27.

Brie, Evelyne, and Yannick Dufresne, 2018. "Replication Data for "Tones from a Narrowing Race: Polling and Online Political Communication during the 2014 Scottish Referendum Campaign"”, doi:10.7910/DVN/RQ7P1F, Harvard Dataverse, V1, UNF:6:yQF8eJmVr+1Xm1WbNPxuSg==

Campbell, et al. 1960. The American Voter. Chicago, IL: University of Chicago Press.

${ }^{53}$ Stefan Stieglitz and Linh Dang-Xuan 2012. 
Carrell, S., and L. Brooks. 2014. Scottish Independence: Salmond Scores Victory over Darling in Fractious Debate. Available from www.theguardian.com/ politics/2014/aug/25/scottish-independence-debatealex-salmond-alistair-darling, accessed 5 August 2015.

Ceci, S., and E. Kain. 1982. Jumping on the Bandwagon with the Underdog: The Impact of Attitude Polls on Polling Behavior. Public Opinion Quarterly 46 (2):228-42.

Chew, C., and G. Eysenbach. 2010. Pandemics in the Age of Twitter: Content Analysis of Tweets during the 2009 H1N1 Outbreak. PloS One 5 (11):e14118.

Chong, D., and J. Druckman. 2007. Framing Theory. Annual Review of Political Science 10:103-26.

Faber, R. J., A. R. Tims, and K. G. Schmitt. 1993. Negative Political Advertising and Voting Intent: The Role of Involvement and Alternative Information Sources. Journal of Advertising 22 (4): $67-76$.

Fridkin, K. L., and P. Kenney. 2011. Variability in Citizens' Reactions to Different Types of Negative Campaigns. American Journal of Political Science 55 (2):307-25.

Garramone, G. 1985. Effects of Negative Political Advertising: The Roles of Sponsor and Rebuttal. Journal of Broadcasting and Electronic Media 29 (2):147-59.

Gayo-Avello, D. 2011. Don't Turn Social Media into Another 'Literary Digest' Poll. Communications of the ACM 54 (10):121-28.

Green, C., N. Morris, J. Brown, and J. Cusick. 2014. Scottish Independence: From Oil and the Economy to the Pound and the Queen, the Hot Topics Driving the Referendum Debate. The Independent, 14 September.

Großer, J., and A. Schram. 2010. Public Opinion Polls, Voter Turnout, and Welfare: An Experimental Study. American Journal of Political Science 54 (3):700-17.

Hallahan, K. 1999. Seven Models of Framing: Implications for Public Relations. Journal of Public Relations Research 11 (3):205-42.

Hamilton, D., and M. Zanna. 1972. Differential Weighting of Favorable and Unfavorable Attributes in Impressions of Personality. Journal of Experimental Research in Personality 6 (2-3):204-12.

Herald Scotland. 2014. Debate Snap Poll Declares Darling Winner. Available from www.heraldscotland. com/news/13173438.Debate-snap-poll-declares-Darling-winner/, accessed 5 August 2015.

Hill, R. P. 1989. An Exploration of Voter Responses to Political Advertisements. Journal of Advertising 18 (4):14-22.

Ito, T. A., J. T. Larsen, N. K. Smith, and J. T. Cacioppo. 1998. Negative Information Weighs More Heavily on the Brain: The Negativity Bias in Evaluative Categorizations. Journal of Personality and Social Psychology 75 (4):887.

Jarymowicz, M., and D. Bar-Tal. 2006. The Dominance of Fear over Hope in the Life of Individuals and Collectives. European Journal of Social Psychology 36 (3):367-92.

Jürgens, P., A. Jungherr, and H. Schoen. 2011. Small Worlds with a Difference: New Gatekeepers and the Filtering of Political Information on Twitter. Proceedings of the 3rd International Web Science Conference, 21.

Kahneman, D., and A. Tversky. 1979. Prospect Theory: An Analysis of Decision Under Risk. Econometrica: Journal of the Econometric Society 47 (2):263-91.

Kanayama, H., and T. Nasukawa. 2006. Fully Automatic Lexicon Expansion for Domain-Oriented Sentiment Analysis. Proceedings of the 2006 Conference on Empirical Methods in Natural Language Processing, 355-63.

Karlsson, M., C. Clerwall, and U. Buskqvist. 2013. Political Public Relations on the Net: A Relationship Management Perspective. Public Relations Journal 7 (4):1-23.

Kernell, S. 1977. Presidential Popularity and Negative Voting: An Alternative Explanation of the Midterm Congressional Decline of the President's Party. American Political Science Review 71 (1):44-66.

Lau, R. R., and G. M. Pomper. 2002. Effectiveness of Negative Campaigning in US Senate Elections. American Journal of Political Science 46 (1):47-66.

LeDuc, L. 2002. Referendums and Elections: How Do Campaigns Differ? Pp. 145-62 in Do Political Campaigns Matter? Campaign Effects in Elections and Referendums, edited by D. M. Farrell and R. Schmitt-Beck. London: Routledge. 
Lengauer, G., and I. Hoeller. 2013. Generic Frame Building in the 2008 Austrian Elections. Public Relations Review 39 (4):303-14.

Liu, B., M. Hu, and J. Cheng. 2005. Opinion Observer: Analyzing and Comparing Opinions on the Web. Proceedings of the 14th International Conference on World Wide Web,342-51.

McAllister, I., and D. Studlar. 1991. Bandwagon, Underdog, or Projection? Opinion Polls and Electoral Choice in Britain, 1979-1987. Journal of Politics 53 (3):720-41.

Macskassy, S., and M. Michelson. 2011. Why do People Retweet? Anti-Homophily Wins the Day! Proceedings of the Fifth International AAAI Conference on Weblogs and Social Media, 209-16.

Mercer, J. 2005. Prospect Theory and Political Science. Annual Review of Political Science 8:1-21.

Merritt, S. 1984. Negative Political Advertising: Some Empirical Findings. Journal of Advertising 13 (3):27-38.

Metaxas, P. T., E. Mustafaraj, and D. Gayo-Avello. 2011. How (Not) to Predict Elections. IEEE Third International Conference on Social Computing (SocialCom), 165-71.

Mislove, A., S. Lehmann, Y.-Y. Ahn, J.-P. Onnela, and J. N. Rosenquist. 2011. Understanding the Demographics of Twitter Users. Proceedings of the Fifth International AAAI Conference on Weblogs and Social Media, 554-57.

Morwitz, V., and C. Pluzinski. 1996. Do Polls Reflect Opinions or do Opinions Reflect Polls? The Impact of Political Polling on Voters' Expectations, Preferences, and Behavior. Journal of Consumer Research 23:53-67.

Nadeau, R., P. Martin, and A. Blais. 1999. Attitude towards Risk-Taking and Individual Choice in the Quebec Referendum on Sovereignty. British Journal of Political Science 29 (3):523-39.

O'Connor, B., R. Balasubramanyan, B. R. Routledge, and N. A. Smith. 2010. From Tweets to Polls: Linking Text Sentiment to Public Opinion Time Series. ICWSM 11:122-29.

Pak, A., and P. Paroubek. 2010. Twitter as a Corpus for Sentiment Analysis and Opinion Mining. Proceedings of LREC 10:1320-26.

Sabato, L. 1981. The Rise of Political Consultants: New Ways of Winning Elections. New York: Basic Books.

Sang, E. T. K., and J. Bos. 2012. Predicting the 2011 Dutch Senate Election Results with Twitter. Proceedings of the Workshop on Semantic Analysis in Social Media 53-60.

Schrott, P. R. 1990. Electoral Consequences of 'Winning' Televised Campaign Debates. Public Opinion Quarterly 54 (4):567-85.

Scottish National Party. 2014. Scaremongering Leaves 'A Bad Taste in the Mouth'. Available from https://www.snp.org/media-centre/news/2012/sep/scaremongering-leaves-bad-taste-mouth, accessed 5 August 2015.

Shapiro, M. A., and R. H. Reiger. 1992. Comparing Positive and Negative Advertising on Radio. Journalism Quarterly 69:135-45.

Shephard, M., and S. Quinlan. 2014. Tipping Point Online, Tripping Point Offline? Available from http:// www.discoversociety.org/2014/04/01/tipping-point-online-tripping-point-offline, accessed 5 August 2015 .

Stieglitz, S., and L. Dang-Xuan. 2012. Political Communication and Influence through Microblogging: An Empirical Analysis of Sentiment in Twitter Messages and Retweet Behavior. System Science (HICSS) 45th Hawaii International Conference, 3500-9.

Strömbäck, J., and S. Kiousis. 2011. Political Public Relations: Principles and Applications. New York: Routledge.

Taylor, P. 1989. Consultants Rise Via the Low Road. Washington Post, 17 January: A1 and A14.

Tumasjan, A., T. O. Sprenger, P. Sandner, and I. Welpe. 2010. Predicting Elections with Twitter: What 140 Characters Reveal about Political Sentiment. International Conference on Web and Social Media 10:178-85.

Wentura, D., K. Rothermund, and P. Bak. 2000. Automatic Vigilance: The Attention-Grabbing Power of Approach- and Avoidance-Related Social Information. Journal of Personality and Social Psychology 78:1024-37.

Witte, K. 1992. Putting the Fear Back into Fear Appeals: The Extended Parallel Process Model. Communications Monographs 59 (4):329-49. 